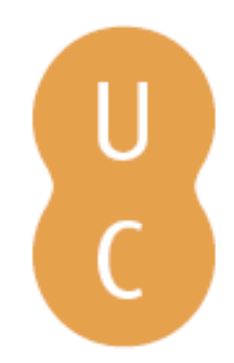

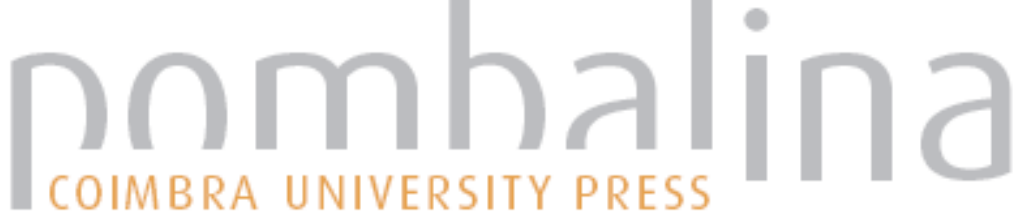

\section{SIGMDL: portal de informação geográfica}

\author{
Autor(es): $\quad$ Gouveia, Maria Manuel
}

Publicado por: Imprensa da Universidade de Coimbra

URL

persistente: URI:http://hdl.handle.net/10316.2/31166

DOI: $\quad$ DOI:http://dx.doi.org/10.14195/978-989-26-0244-8_75

Accessed : $\quad$ 26-Apr-2023 15:03:48

A navegação consulta e descarregamento dos títulos inseridos nas Bibliotecas Digitais UC Digitalis, UC Pombalina e UC Impactum, pressupõem a aceitação plena e sem reservas dos Termos e Condições de Uso destas Bibliotecas Digitais, disponíveis em https://digitalis.uc.pt/pt-pt/termos.

Conforme exposto nos referidos Termos e Condições de Uso, o descarregamento de títulos de acesso restrito requer uma licença válida de autorização devendo o utilizador aceder ao(s) documento(s) a partir de um endereço de IP da instituição detentora da supramencionada licença.

Ao utilizador é apenas permitido o descarregamento para uso pessoal, pelo que o emprego do(s) título(s) descarregado(s) para outro fim, designadamente comercial, carece de autorização do respetivo autor ou editor da obra.

Na medida em que todas as obras da UC Digitalis se encontram protegidas pelo Código do Direito de Autor e Direitos Conexos e demais legislação aplicável, toda a cópia, parcial ou total, deste documento, nos casos em que é legalmente admitida, deverá conter ou fazer-se acompanhar por este aviso.

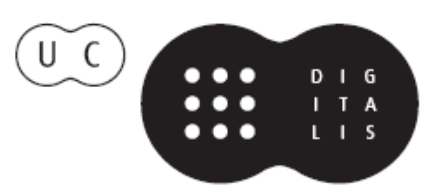




\section{TRUNFOS DE UMA}

\section{EOGRAFIA ACIVA}

\section{DESENVOLVIMENTO LOCAL,}

AMBIENTE,

ORDENAMENTO

E TECNOLOGIA

Norberto Santos

Lúcio Cunha

COORDENAÇÃO 
Maria Manuel Gouveia

Câmara Municipal de Mirandela, Serviço de Sistemas de Informação Geográfica

\author{
SIGMDL - PORTAL DE INFORMAÇÁO GEOGRÁFICA
}

\title{
INTRODUÇÃO
}

Os Serviços de Sistemas de Informação Geográfica (SIG) da Câmara de Mirandela funcionam desde 2003, tendo, desde entáo, sido obtida, tratada e actualizada cartografia de base e alfanumérica, com o intuito de se produzirem saídas gráficas de qualidade que apoiassem as actividades de decisão, bem como satisfizessem as necessidades dos munícipes.

Em 2006, contando com a consultoria e apoio da empresa ESRI-Portugal, após se ter verificado a necessidade de uma gestão mais eficiente da informação cartográfica de base e alfanumérica, definiu-se um modelo de dados (onde se identifica a informaçáo de ordem espacial existente na Câmara Municipal de Mirandela) e procedeu-se à sua centralização num servidor que, actualmente, permite a edição controlada, a garantia de segurança dos dados e o acesso à informação cartográfica de base e alfanumérica de forma única e actualizada, em reduzidos espaços de tempo.

O Portal de Informação Geográfica da Câmara Municipal de Mirandela, denominado SIGMDL, surge na sequência da materialização de uma gestão mais eficiente da informação cartográfica de base e alfanumérica existente.

\section{SIGMDL - PORTAL DE INFORMAÇÃO GEOGRÁFICA}

O Portal de Informação Geográfica denominado SIGMDL surgiu, em 2006, a par da crescente necessidade de se efectuar uma gestão mais eficiente da informação cartográfica de base e alfanumérica que se encontrava dispersa por vários sectores da Câmara Municipal de Mirandela, procedendo-se, assim, à sua organização (através da construção de um modelo de dados) e à sua centralizaçấo num servidor, constituindo, assim, o culminar de um trabalho de harmonização de um grande manancial de informação espacial (cartografia de base e alfanumérica).

O Portal de Informação Geográfica SIGMDL assenta na utilização da internet e em software adquirido à empresa ESRI-Portugal. A arquitectura do sistema (figura 1) baseia-se na centralização da informação espacial (cartográfica de base e alfanumérica) num servidor, no qual está instalado o programa ArcGIS Server. A esse servidor estão ligados os postos de trabalho de três operadores de SIG, estando estes equipados com um browser e o programa ArcView 9.3, podendo, assim, editar, visualizar, consultar, imprimir e publicar 
toda a informação cartográfica e alfanumérica. Os utilizadores finais necessitam, apenas, de um browser nos seus terminais, para acederem a toda a informação, podendo, actualmente, visualizar, consultar e imprimir a informação cartográfica de base e alfanumérica de que necessitam.

Figura 1 - Arquitectura do sistema

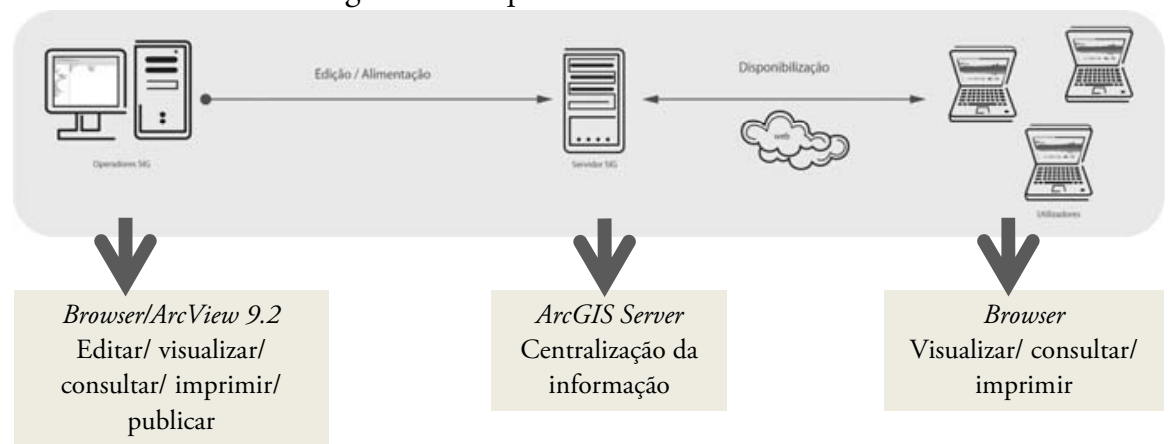

Durante o ano de 2007 procedeu-se à costumizaçáo do seu layout, bem como à selecçáo criteriosa de toda a informação cartográfica de base e alfanumérica a disponibilizar e, posteriormente, a 19 de Novembro de 2008 (Dia dos Sistemas de Informação Geográfica), colocou-se o Portal de Informação Geográfica SIGMDL on-line, podendo este ser consultado através do sítio www.cm-mirandela.pt, onde se tem que escolher o ícone:

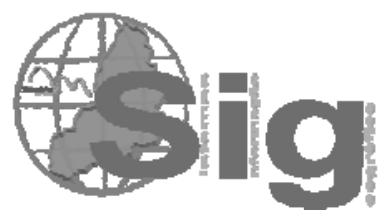

Após se escolher o ícone acima indicado, abre-se uma janela onde se encontram, até ao momento, onze caixas que correspondem a onze diferentes projectos relacionados com as seguintes temáticas:

- Ambiente;

- Demografia;

- Indústria;

- Ortofotomapas;

- Plano Director Municipal;

- Plantas de Localização;

- Protecção Civil;

- Património Histórico;

- Serviços;

- Toponímia;

- Turismo. 
Figura 2 - Aspecto do projecto «Ambiente».

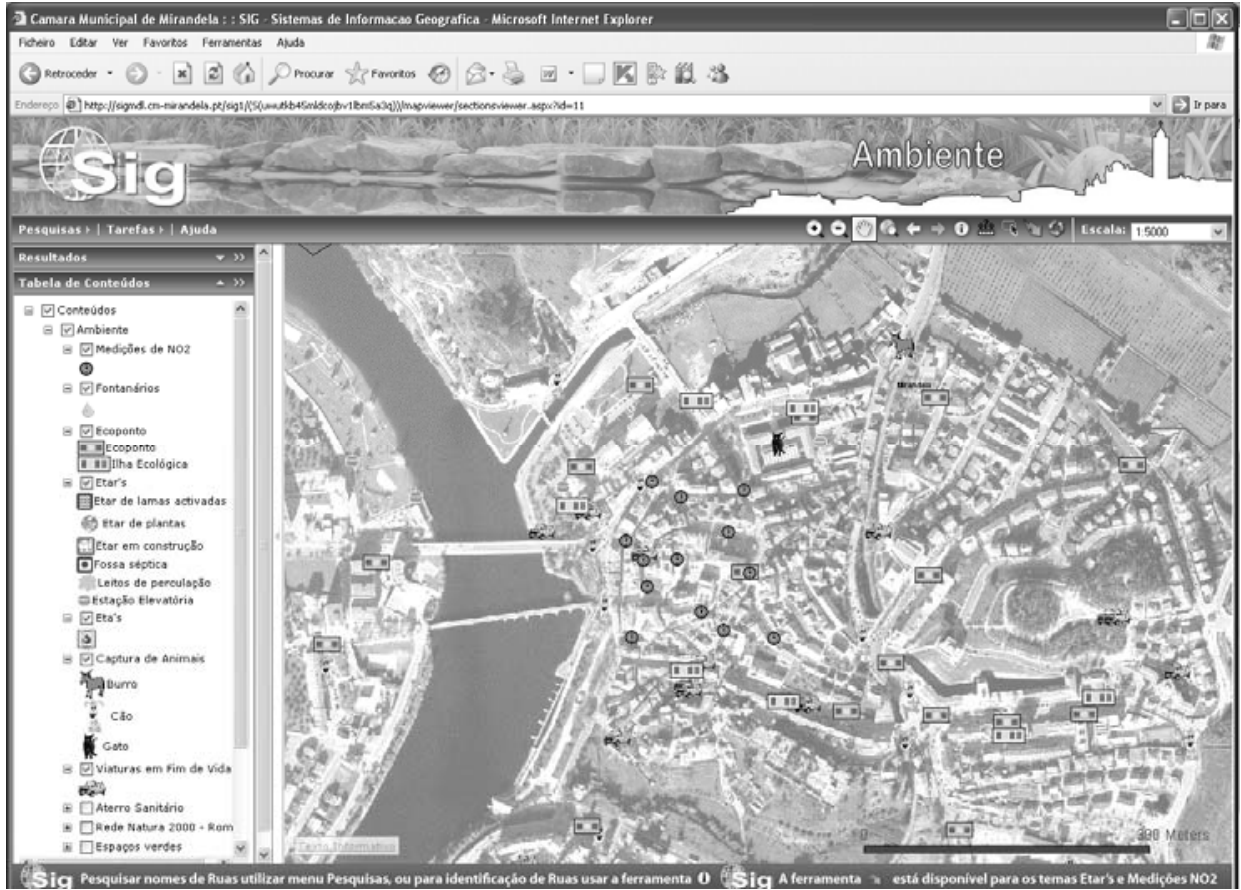

Cada uma das onze caixas dá acesso a um diferente projecto, onde se encontra informação específica da temática que se escolheu. Por exemplo, se se escolher o projecto "Ambiente», pode aceder-se a uma quantidade variada de informação como se pode ver na legenda da figura 2.

A disponibilização de um grande manancial de informação cartográfica de base e alfanumérica, através do Portal de Informação Geográfica SIGMDL, permite que se atinjam os seguintes objectivos:

- Disponibilização amigável e gratuita de informação cartográfica de base e alfanumérica ao cidadão comum e a diversas instituiçôes públicas e privadas que tenham ou posssam vir a ter interesse no território do concelho de Mirandela;

- Aumento do número de utilizadores de informaçáo geográfica, quer nos serviços internos da Câmara Municipal, quer em serviços externos, contribuindo-se, assim, para o direito ao acesso à informação;

- Aproximaçáo do cidadão com a autarquia, aumentando a sua capacidade de participação e de acesso a processos;

- Contribuição para a dimuição da burocracia;

- Acesso remoto à informação cartográfica de base e alfanumérica com possibilidade de realização de análises espaciais;

- Aumento do rigor e da transparência da informação cartográfica de base e alfanumérica;

- Eliminação da redundância e da duplicação de informação cartográfica de base e alfanumérica. 
Actualmente, as funcionalidades disponíveis no Portal de Informação Geográfica SIGMDL, compreendem:

- Serviços de visualização, tais como, aproximar, afastar, arrastar, extensão total e refresh do mapa;

- Serviços de pesquisa, tais como, pesquisas livres e pesquisas orientadas;

- Outros serviços, tais como, identificação de objectos, selecção de registos, mediçóes, escolha de uma escala fixa/de outras escalas, hyperlink para ficheiros em variados formatos e menu de ajuda.

Até ao momento, estão referenciados como utilizadores do Portal de Informação Geográfica SIGMDL, os munícipes, os serviços internos da Câmara Municipal, algumas entidades externas públicas e privadas e o público em geral. No entanto, ainda não existe o registo destes mesmos utilizadores, nem se sabe qual o seu grau de satisfação.

Por enquanto, o que se sabe é que a utilização deste Portal de Informação Geográfica garante uma maior rapidez no que respeita à eficácia na realizaçáo dos trabalhos/projectos, uma maior eficácia na análise da informação (cartográfica de base e alfanumérica) e na tomada de decisão, um aumento do conhecimento do território e da participaçáo pública e, de futuro, permitirá uma maior descentralização de alguns serviços.

As principais dificuldades que se sentiram durante a fase de implementação e que se sentem durante a fase de manutenção do Portal de Informação Geográfica SIGMDL, estão relacionadas com:

- Ligaçóes em rede;

- Compatibilizaçáo de software actualizado com software já existente;

- Manutenção do servidor onde se encontra a informação cartográfica de base e alfanumérica;

- Formação dos operadores de SIG e dos utilizadores do Portal de Informação Geográfica.

\section{DESENVOLVIMENTOS FUTUROS}

O Portal de Informação Geográfica SIGMDL está em constante actualização no que respeita à introduçáo de novos serviços (tais como o de download) e novos projectos, ao seu aspecto gráfico e ao seu conteúdo.

De modo a se ir ao encontro com a Directiva INSPIRE, pretendem introduzir-se e publicar-se on-line todos os metadados (recorrendo-se ao software MIG Editor 2.2, disponível no sítio do SNIG) referentes à informação já disponível, bem como compatibilizar o Portal de Informação Geográfica SIGMDL com outros portais de informação geográfica que contemplam informação a outras escalas, tais como a nacional, regional e europeia.

Brevemente, pretende tornar-se o Portal de Informação Geográfica SIGMDL mais amigável, tendo que, para tal, se proceder à realização de um inquérito, on-line, de satisfação relacionado com a utilização do mesmo.

Pretende, ainda, proceder-se ao estabelecimento de parcerias com diversas entidades nacionais e internacionais que permitam dar continuidade ao desenvolvimento do Portal de Informação Geográfica SIGMDL, pois as experiências vividas por outras entidades poderáo trazer bons ensinamentos que farâo progredir correctamente esta infra-estrutura. 


\section{CONCLUSÃO}

Através da criação e manutenção do Portal de Informação Geográfica SIGMDL, a Câmara Municpal de Mirandela tem a possibilidade de disponibilizar, de forma amigável e gratuita, a visualização, a pesquisa, a impressão e, de futuro, o download de informação cartográfica de base e alfanumérica actualizada, a todos os cidadãos, garantindo, também as mesmas bases de trabalho para as actividades de tomada de decisão no que respeita ao ordenamento e gestáo do território, tornando-se, assim, possível uma relação cada vez melhor com os munícipes, incentivando, de forma atractiva, a sua participaçáo e, consequentemente, a sua melhoria das condiçóes de vida. 